\title{
Article
}

\section{Development of the Neural Processing of Vocal Emotion during the First Year of Life}

Zhao, Chen, Schiessl, Ingo, Wan, Ming Wai, Chronaki, Georgia and Abel, Kathryn

Available at http://clok.uclan.ac.uk/35862/

Zhao, Chen, Schiessl, Ingo, Wan, Ming Wai, Chronaki, Georgia ORCID: 00000001-5146-2510 and Abel, Kathryn (2021) Development of the Neural Processing of Vocal Emotion during the First Year of Life. Child Neuropsychology, 27 (3). pp. 333-350. ISSN 0929-7049

It is advisable to refer to the publisher's version if you intend to cite from the work. http://dx.doi.org/10.1080/09297049.2020.1853090

For more information about UCLan's research in this area go to http://www.uclan.ac.uk/researchgroups/ and search for <name of research Group>.

For information about Research generally at UCLan please go to http://www.uclan.ac.uk/research/

All outputs in CLoK are protected by Intellectual Property Rights law, including Copyright law. Copyright, IPR and Moral Rights for the works on this site are retained by the individual authors and/or other copyright owners. Terms and conditions for use of this material are defined in the policies page.

\section{CLoK}

Central Lancashire online Knowledge www.clok.uclan.ac.uk

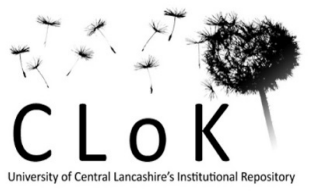


1 Title: Development of the Neural Processing of Vocal Emotion during the First Year of Life 2

3 Running title: Vocal Emotion Processing in Infants

4

5

6 


\section{Abstract}

2 Human infants are 'wired' to respond to social information, an important capacity for

3 survival. The ability to discriminate vocal emotion in others is likely to play a key role in

4 successful social interactions with caregivers, which facilitate the rapid social-

5 communicative development that infants typically undergo in the latter half of their first

6 year. Infants have voice-sensitive brain regions that have been shown previously to be

7 responsive to emotional prosody by 7 months. This study aimed to investigate the

8 developmental trajectory of vocal emotion processing in temporal regions using functional

9 near infrared spectroscopy (fNIRS) to measure brain sensitivity to angry, happy and neutral vocalisations in the same infant at 6, 9, and 12 months. We found significant and increasing temporal cortical activation in response to vocal emotional stimuli over the 3 time points, suggesting consistent enhanced responses for happy compared to angry vocalisations, and vocal anger sensitivity is developing incrementally. The findings suggest that the neural processing of angry and happy prosody may follow distinct developmental pathways and is gradually 'tuned' to become specialised between 6 and 12 months. This first longitudinal study of vocal emotion brain processing between 6 and 12 months highlights the need for more research to understand what drives typical and atypical social cognitive development across infancy and for follow-up into the second year.

Key words: fNIRS, infant, social-emotional, voice, prosody 


\section{Introduction}

Voice recognition is fundamental to human social interaction and has long been investigated as a foundation for social cognition and language development in infants (Blasi et al., 2015; Lloyd-Fox et al., 2013) and children (Chronaki, Benikos, Fairchild, \& SonugaBarke, 2015; Chronaki, Wigelsworth, Pell, \& Kotz, 2018). Studies in utero and of newborns suggest that humans are born with a readiness to discriminate their mother's voice (Kisilevsky et al., 2003; Ockleford, Vince, Layton, \& Reader, 1988). Neuroimaging suggests that the bilateral superior temporal cortices are implicated as voice-selective areas in children (Rogier, Roux, Belin, Bonnet-Brilhault, \& Bruneau, 2010) and adults (Belin \& Zatorre, 2000; Belin, Zatorre, Lafaille, Ahad, \& Pike, 2000). Infants do not show distinct neural responses to unfamiliar human voices before the age of 4 months, and their brains may develop neural sensitivity to human voices by six or seven months of age (Grossmann, Oberecker, Koch, \& Friederici, 2010; McDonald et al., 2019).

Emotional prosody refers to changes in the speaker's vocal intonation according to their emotional state (Banse \& Scherer, 1996; Hargrove, 1997). The ability of infants to distinguish emotional prosodic features in voices may play a key role in a range of developmental domains, including infant-caregiver attachment formation (Trevarthen, 2017), infant social cognition, such as social referencing (Mumme, Fernald, \& Herrera, 1996) and infant learning (Doan, 2010). Behavioural studies suggest that infants consistently prefer happy voices from birth (Mastropieri \& Turkewitz, 1999; Singh, Morgan, \& Best, 2002) and behaviourally respond preferentially to their mother's speech at one month, but only when the mother's speech has natural prosody (Mehler, Bertoncini, Barriere, \& Jassikgerschenfeld, 1978). By five months, infants are able to detect prosodic change between happy and sad vocalisations (Blasi et al., 2015; Blasi et al., 2011; Walker-Andrews \& 
1 Grolnick, 1983) and respond behaviourally differently to positive and negative infant-

2 directed speech (Fernald, 1993). The ability to extract prosodic features from vocal sounds provides the pre-verbal infant with salient information about the status of their environment. Infants' wellestablished preference for infant-directed speech (Cooper \& Aslin, 1990; Hayashi, Tamekawa, \& Kiritani, 2001) seems to be based on the heightened valance of positive emotion and wider range of expressed emotion used by parents (Panneton, Kitamura, Mattock, \& Burnham, 2006; Singh et al., 2002) and not on pitch per se (Kitamura \& Burnham, 1998). Positive vocal prosody, such as that found in infant-directed speech, may signal safety and positive social value to the infant (Lohaus, Keller, Ball, Elben, \& Voelker, 2001), while vocal negativity provides information about the potential threat or danger in the environment (Striano \& Rochat, 2000; Vaish \& Striano, 2004). The neural correlates of infant behavioural preferences may start to become apparent in specialised cortical and subcortical brain responses to emotional vocalisations by around seven months of age (review by Grossmann and Johnson, 2007). Studies using a range of brain imaging techniques suggest that this neural sensitivity may emerge as early as the first month of life (Blasi et al., 2015; Blasi et al., 2011; Zhang, Zhou, Hou, Cui, \& Zhou, 2017). An fNIRS study of sleeping newborns reported that emotional (happy, angry and fearful) vocalisations compared with neutral pseudo-speech elicited greater right temporal activation (Zhang et al., 2017). Two fMRI studies reported insular and bilateral frontal responses to sad vocalisations in sleeping infants aged 3-7 months (Blasi et al., 2015; Blasi et al., 2011). Furthermore, an fNIRS study of awake 7-month-old infants found increased right inferior frontal and superior temporal cortical responses to happy and angry, but not to neutral, speech respectively (Grossmann et al., 2010). Neural imaging studies on vocal 
emotional processing in infants from 8 months onwards are scarce (see Morningstar, Nelson, \& Dirks, 2018). One recent ERP study showed an enhanced central and temporal response to crying and laughing compared to neutral vocalisations at 8 months (Missana, Altvater-Mackensen, \& Grossmann, 2017).

While several studies implicate the temporal region for infant vocal and vocal emotion processing, understanding of this neural response, especially over the first year, is still very limited. Lloyd-Fox et al. (2017) conducted the only longitudinal between-subjects study to date on voice sensitivity development in human infants. Tracking a rural Gambian cohort of infants aged between 2 to 24 months of age, they reported stable and relatively consistent early functional specialisation of selective neural response to human voice from 9 - 13 months onwards (Lloyd-Fox et al., 2017). Whether infants become able to discriminate prosodic vocal content along the same timeline has not yet been investigated, yet this seems a very important competence to develop as emotional vocalisations carry information of high social value.

The current study represents the first longitudinal, within-subject fNIRS study of infant vocal emotion processing at 6, 9 and 12 months of age. We hypothesised that, at all time points, infants would show increased brain responses to emotional (angry, happy) compared to neutral vocalisations in voice-sensitive temporal regions. Second, we anticipated that infant neural responses to vocal emotional stimuli would become stronger with increasing infant age. Third, we explored whether developmental trajectories of prosodic processing would differ as a function of emotion type. No specific prediction was made given that both positive and negative prosody was expected to carry high social value, although studies suggest an early happy vocal preference from birth (Mastropieri \& Turkewitz, 1999; Singh et al., 2002). 


\section{Methods}

\section{Participants}

Forty infants of healthy mothers were recruited to the present study from three

Manchester (UK) community health centres. All infants were born at the normal birth weight (>2500 g); 39 were full term (37-42 weeks gestation); one was born at 36 weeks gestation (corrected gestational age). All infants were typically developing and none had hearing difficulties according to parental report. Mothers consented for their infants. The UK National Health Service ethics committee approved the study (Ref: 15/NW/0684).

Forty infants were tested at 6 months (20 female, 20 male, age range: 175 - 214 days, $\mathrm{M}=189.48$ days, $\mathrm{SD}=9.27), 39$ were re-tested at 9 months (19 female, 20 male; age range: 263 - 302 days, $M=279.08$ days, $S D=9.46$; drop out: $N=1$ ), and 38 infants were retested at 12 months (18 female, 20 male; age range: 360 - 394 days, $M=377.24$ days, SD= 8.61 ; drop out: $N=1$ ). Figure 1 describes the numbers participated and analysed at each time point.

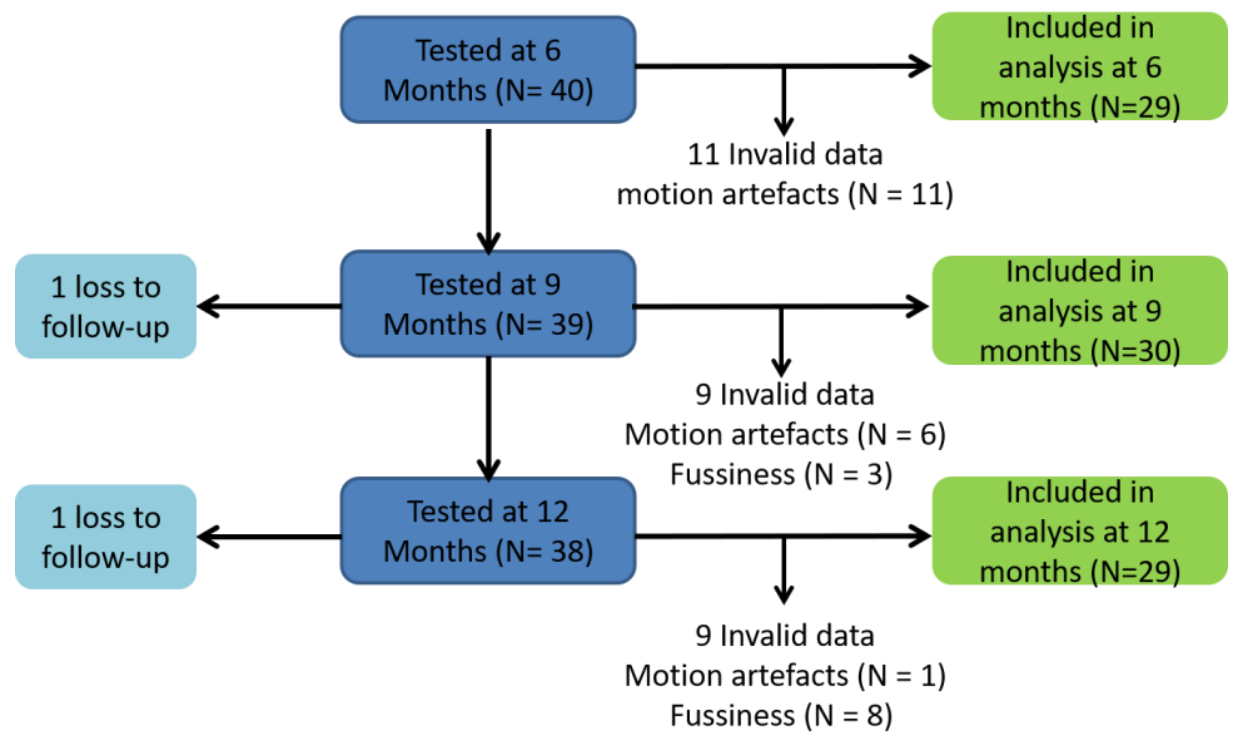

Figure 1 Total number of infants tested and included in analysis at 6, 9, and 12 months. 
Figure 2 presents the experimental paradigm used at all three time points. Infants

wore the NIRS headband, sat on their mothers' laps in front of a laptop during the task and

listened to the vocal stimuli. The task started with a $20 \mathrm{sec}$ rest period, followed by a $5 \mathrm{sec}$

trial presented through loudspeakers $(\mathrm{SPL}=70 \mathrm{~dB})$. Consistent with previous research

(Grossmann et al., 2010), a 5 sec silent cartoon was played along with each trial to attract

infants' attention and reduce motion artefacts. After each trial, a 10 sec silent baseline

(consisted of a 9 sec post-stimulus baseline and a 1-sec pre-stimulus baseline) along with

the blurred cartoon was presented (Blasi et al., 2015; Blasi et al., 2011; Lloyd-Fox, Blasi,

Mercure, Elwell, \& Johnson, 2012). The task was presented with PsychoPy software (Peirce,

2007). The same emotional expression did not occur consecutively. There were 8 trials per

trials. The total length of the testing session was 6 minutes and 20 seconds.
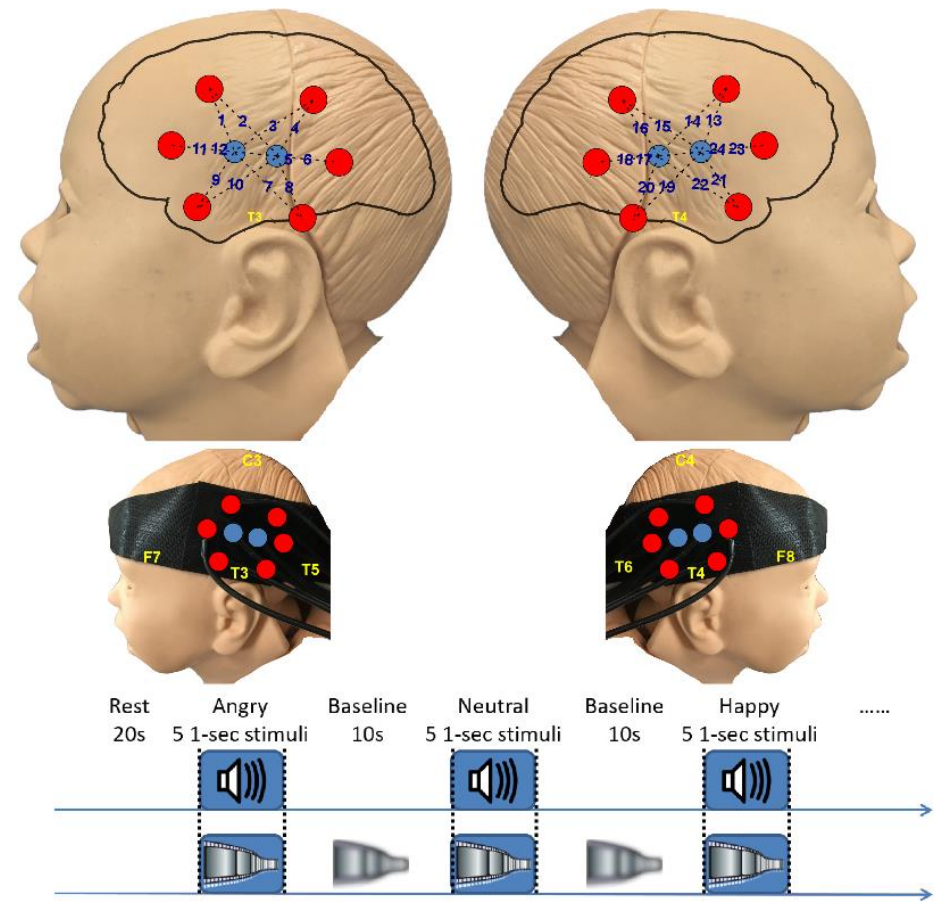

Figure 2. Study experimental task design and channel distribution. The head model illustrates the source detector distribution where red dots represent sources (6 in each 
hemisphere) and blue dots represent detectors ( 2 in each hemisphere). Sources and detectors from 12 recording channels in each hemisphere, which are marked in purple numbers (upper head models), and are held by Velcro head band. Scalp landmarks with respect to 10-20 system are marked in yellow (middle head models). The bottom streamline demonstrates the timeline of the experimental task stimulus presentation and baseline.

\section{Vocal emotional stimuli}

The stimulus material consisted of 15 female non-linguistic vocalisations of angry, happy prosody and neutral vocalisations (interjection 'ah') from a well-validated battery of vocal emotional expressions (Maurage, Joassin, Philippot, \& Campanella, 2007). This battery has high internal consistency for each emotion set and high levels of specificity independence between the ratings in the different emotion sets (Maurage et al., 2007).

These stimuli have been validated in previous research in children of different ages

(Chronaki et al., 2015; Chronaki et al., 2012). Five normalised 1 sec stimuli from the same emotion condition were formed sequentially into a $5 \mathrm{sec}$ trial.

All vocal stimuli were normalised with Praat sound-analysis software (Boersma \& van Heuven, 2001) to the same duration and mean intensity (see Table 1 in the Appendix for details on stimuli acoustic properties). Vocal emotional stimuli were the same at all three time points.

\section{Data acquisition}

During functional cerebral activation, the fNIRS system measures the changes in attenuation of near infrared light. These changes in attenuation are caused by changes in blood volume and the ratio of oxygenated and deoxygenated blood caused by the haemodynamic response (Villringer \& Chance, 1997). In the present study, infants' cerebral responses were recorded with a multichannel NIRS data collection system. The system was built by Biomedical Optics Research Laboratory, (Dept. of Medical Physics and 
1 wavelengths and $10 \mathrm{~Hz}$ sampling rate (Everdell et al., 2005). Two detectors and six sources

2 formed 12 source-detector pairs in each hemisphere and were distributed at temporal

3 regions which have been shown to be voice sensitive in previous research in infants

4 (Grossmann et al., 2010; Lloyd-Fox et al., 2012; Pena et al., 2003; Taga \& Asakawa, 2007)

5 and adults (Belin et al., 2000; Ethofer et al., 2006; Grandjean et al., 2005). To achieve the

6 best spatial sensitivity profile for infants (Fukui, Ajichi, \& Okada, 2003), the distances

7 between source and detectors were fixed between 1.5 and $2.5 \mathrm{~cm}$. Channels were

8 distributed according to the $10-20$ system and attached to a custom-made Velcro headband.

9 According to the head growth standards from the World Health Organisation (World Health

Organization (WHO), 2003), and from previous infants imaging studies (Li et al., 2015; Lloyd-

Fox et al., 2017), the head circumference and skull thickness of 6-to 12-month-old infants does not change significantly. Therefore, the application of a fixed source-detector array across three age time points is reasonable and practical (Lloyd-Fox et al., 2017). The headband was adjusted by calculating the distance between the glabella and the ear, ensuring that T3 and T4 are between the two bottom sources in each hemisphere. This procedure was carried out for all the infants at each time point. The locations of the channels are presented in Figure 2. without large motion artefacts for at least four out of eight trials per condition, based on videotaped observations of the experimental task. The datasets included (6 months: $\mathrm{N}=29$; 9 months: $\mathrm{N}=30 ; 12$ months: $\mathrm{N}=29$ ) were of a rate within the standard range for infant NIRS studies ( $40 \%$ on average is an accepted rejection rate from previous studies, see 
point was determined by a power analysis using G*power (Faul, Erdfelder, Lang, \& Buchner, 2007). This indicated that a sample size of $\mathrm{N}=21$ would give $80 \%$ power to achieve a medium effect size $f=0.29$ (Cohen, 1969) p.348). Our sample size is consistent with previous fNIRS studies in similarly aged infants (Grossmann et al., 2010; Zhang et al., 2017). The included datasets were filtered at 0.01 to $0.5 \mathrm{~Hz}$ with a $3 \mathrm{rd}$ order Butterworth filter, to eliminate slow drifts, instrument noise and physiological artefacts such as heartbeats (Cooper et al., 2012; Fox, Wagner, Shrock, Tager-Flusberg, \& Nelson, 2013; Grossmann et al., 2010), then converted to optical density data in HOMER2 NIRS toolbox (version 2.1, http://homer-fnirs.org/, Huppert et al., 2009). The remaining artefacts were identified on a channel by channel basis with the algorithm 'hmrMotionArtifactByChannel' implemented in the HOMER2. Within the time interval (tMotion), if the change of the signal amplitude exceeded the threshold (AMPthresh) or the standard deviation changes were greater than a factor (STDEVthresh) multiplied by the original channel standard deviation, the time period (tMask time before and after the motion artefact) was marked as artefacts. The time period of motion artefact within the channel was corrected with a cubic spline interpolation algorithm with p set to 0.99 as recommended (Cooper et al., 2012;

Scholkmann, Spichtig, Muehlemann, \& Wolf, 2010). Since the algorithm works on a channel by channel basis, the actual standard deviation threshold for the motion artefact varies according to the standard deviation of the original channel; the setting of the STDEVthresh is the multiplication factor rather than a fixed threshold (i.e. in the current study the standard deviation threshold is $20 *$ standard deviation of the channel). This means that the standard deviation threshold varies from channel to channel and subject to subject. All the values were set as follows: tMotion=5s; tMask=1s; STDEVthresh=20; AMPthresh=5. 
concentration changes in HOMER2 and averaged across trials in the same emotional condition within each dataset, with the time window of $1 \mathrm{sec}$ before and $15 \mathrm{~s}$ after the stimulation onset. The averaged time course of each channel was corrected by subtracting the mean of the $1 \mathrm{sec}$ before the stimulation. The analysis focused on Oxy-Haemoglobin concentration changes which seem to be a sensitive indicator of changes in cerebral blood flow (Grossmann et al., 2010; Meek, 2002). Based on earlier work showing that the haemodynamic response reaches the peak around 2 to 4 sec post stimulus (Brigadoi et al., 2014), we targeted a time window of 2 sec to 9 sec after stimulus onset. Mean amplitudes of cortical haemodynamic responses (Oxy- and Deoxy-Haemoglobin waveforms) were averaged over the time window of $2 \mathrm{sec}$ to $9 \mathrm{sec}$ after stimulus onset.

Repeated measures Analyses of Variance (ANOVA) were initially carried out to identify emotion sensitive channels for which there were significant differences in OxyHaemoglobin concentration change. Averaged haemodynamic responses were analysed by emotion condition (angry, happy, neutral), followed by post-hoc pairwise comparisons for each age (6, 9 and 12 months). Five channels showed significant Oxy-Haemoglobin concentration changes to emotional prosody at 6, 9 and 12 months (Table 1). Then we focused on the 21 infants with valid data at all time points, and conducted a 3-way repeated measures ANOVA with age (6, 9 and 12 months), emotion (angry, happy, neutral) and location (emotion sensitive channel 2, 9, 14, 16, and 21) as within-subject factors, and OxyHaemoglobin concentration change as the dependent measure. Partial eta-squared (Cohen, 1973; Kennedy, 1970) was used to estimate main effect and contrast effect sizes, with thresholds of $0.02,0.13$, and 0.26 to indicate a small, medium and large effect size, respectively (Murphy, Myors, \& Wolach, 2014). 
2 2017), a false discovery rate (FDR, Benjamini and Hochberg, 1995) correction was applied to resolve the issue of multiple statistical comparisons. $\mathrm{P}$ values arranged in ascending order

4 with an order number index allowed us to calculate adjusted $\alpha$ values: $\alpha$ adjust $=$ (order

5 index / total number of comparisons) $* 0.05 . P$ value $<$ adjusted $\alpha$ value remained significant 6 (Field, Miles, \& Field, 2012). 


\section{Results}

The participant characteristics of those included in the final datasets analysis are described in Figure 1. For the included datasets, the percentages of discarded trials at each age point are (mean $\pm S D$ ): at 6 months $3.74 \% \pm 3.40 \%$; at 9 months $10.00 \% \pm 14.72 \%$; at 12 months $4.74 \% \pm 11.12 \%$.

The emotion sensitive channels at each time point were identified and shown in

Table 1; those that have passed FDR correction are shown in Figure 3. Both happy (channel 16) and angry (channel 2) vocalisations evoked significantly greater neural responses at 6 months; happy vocalisations have evoked significantly greater neural responses at 9 (channel 21) and 12 (channel 9) months.

Additionally, a 3 (emotion) x 3 (age) x 5 (channel) ANOVA showed a significant main effect of emotion only $\left(F(2,40)=3.86, p=.029, \eta_{p}^{2}=.16\right)$ and not age $(F(2,40)=1.22, p$ $\left.=.307, \eta_{p}^{2}=.06\right)$ or channel $\left(F(2,80)=.86, p=.494, \eta_{p}^{2}=.04\right)$. Pairwise comparisons highlighted a significant happy $>$ angry effect $\left(F(1,20)=8.01, p=.010, \eta_{p}^{2}=.29\right.$, survived FDR correction), but not between happy and neutral or angry and neutral. Further, a significant age $x$ emotion $x$ location interaction effect emerged $(F(16,320)=2.04, p=.011$, $\left.\eta_{\mathrm{p}}^{2}=.09\right)$

To further interpret the 3-way interaction effect, an age $\mathrm{x}$ emotion repeated measures ANOVA was conducted for each channel location, followed by pairwise comparisons. There was no significant main effect or interaction in channel 2,14 , and 21 . A significant main effect of emotion was found in channel $9\left(F(2,40)=4.39, p=.019, \eta_{p}^{2}\right.$ $=.18)$, which was attributed to the happy $>$ angry condition $\left(F(1,20)=7.83, p=.011, \eta_{p}^{2}\right.$ $=.28$, survived FDR correction); age and interaction effects were not significant. In channel 16 , a significant age effect $\left(F(2,40)=3.40, p=.043, \eta_{p}^{2}=.15\right)$ was due mainly to the 
1 increased Oxy-Haemoglobin concentration changes at $12>9$ months $(F(1,20)=8.02, p$

$2=.010, \eta_{\mathrm{p}}^{2}=.29$, survived FDR correction). The effect of emotion was not significant in

3 channel 16 , while an age $x$ emotion interaction $\left(F(4,80)=2.98, p=.024, \eta_{p}^{2}=.13\right)$ was

4 localised to the happy vs. angry comparisons at 6 to 9 months and 6 to 12 months $(F(1,20)$

$5=14.80, p=.001, \eta_{p}^{2}=.43 ;$ and $F(1,20)=8.32, p=.009, \eta_{p}^{2}=.29$ respectively, both survived

6 FDR correction). Responses were stronger for happy than angry vocalisations at 6 months

7 and reversed (angry > happy) at 9 and 12 months (see Figure 4). To further test for change

8 in neural sensitivity to angry prosody in channel 16 over time, a Pearson correlation was

9 conducted using data over 6-12 months and found stronger local neural response with age

$10 \quad(r=.27, p=.030)$.

11

12

13

14

15

16

17

18

19
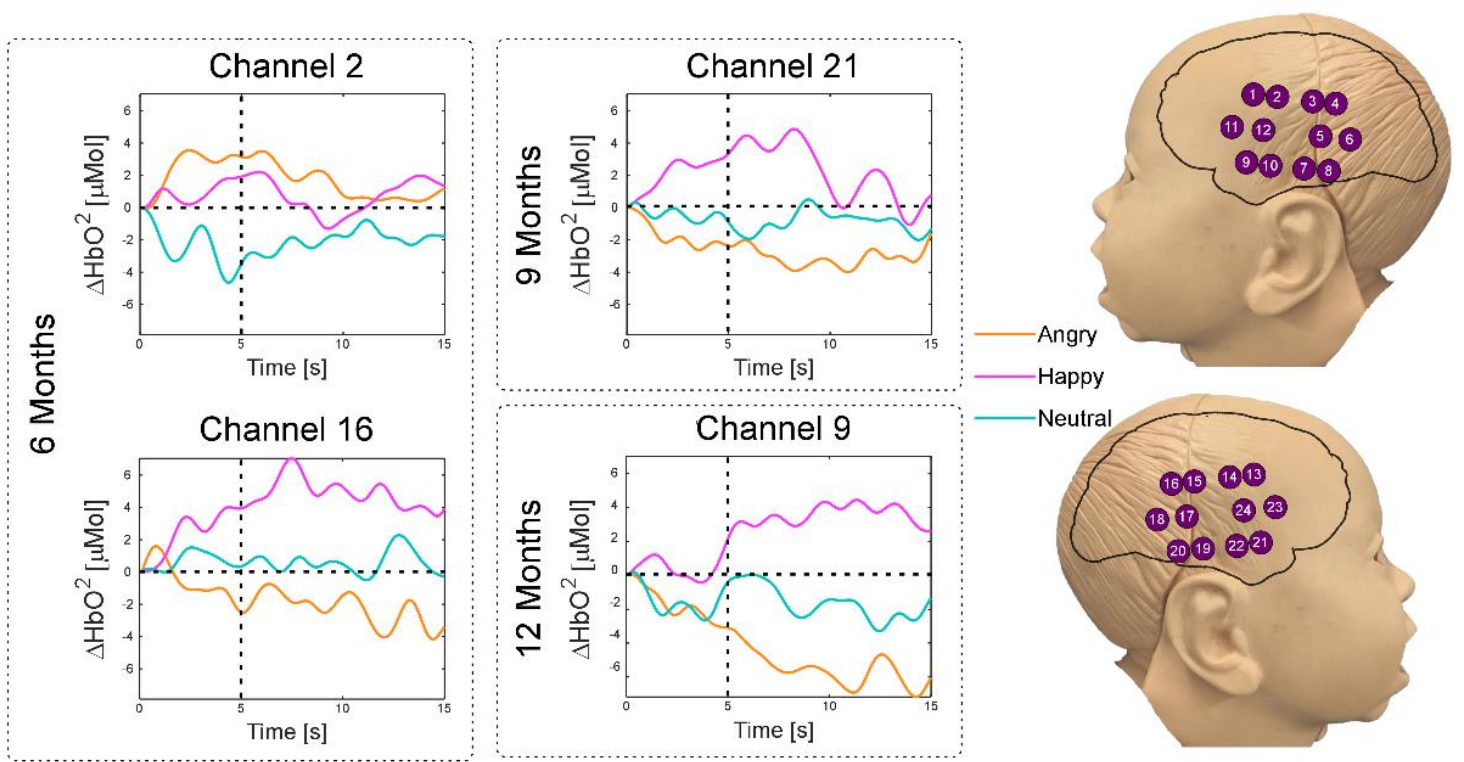

Figure 3 Averaged time courses of Oxy-Haemoglobin concentration changes in channels showing significant emotion effect at each age point (6,9 and 12 month) per vocal emotion (Angry in orange, Happy in pink and Neutral in light blue) in the time period of $15 \mathrm{sec}$ ( $5 \mathrm{sec}$ stimulus and $10 \mathrm{sec}$ baseline). The channel location is marked in the right panel. The stimulus end time is marked by the dashed line. The time (in sec) and change in amplitude $(\mu \mathrm{Mol})$ are in the $\mathrm{x}$ and $\mathrm{y}$ axis respectively. 
Table 1. Summary of emotion (Angry, Happy, Neutral) ANOVA effects on Oxy-Haemoglobin concentration changes at 6, 9 and 12 months.

\begin{tabular}{|c|c|c|c|c|c|c|c|c|c|c|}
\hline \multirow[t]{2}{*}{ Channel } & \multirow[t]{2}{*}{ Emotion } & \multirow{2}{*}{$\begin{array}{c}\text { Mean } \pm \\
\text { SEM }\end{array}$} & \multicolumn{4}{|c|}{ ANOVA } & \multicolumn{3}{|c|}{ Pairwise Comparisons } & \multirow{2}{*}{$\begin{array}{c}\text { Adjusted } \alpha \\
\text { value } \\
\alpha_{\text {adjust }}\end{array}$} \\
\hline & & & $F$ & $\mathrm{p}$ & $\begin{array}{l}\text { Partial Eta- } \\
\text { squared }\end{array}$ & Comparison $^{a}$ & $\mathrm{~F}$ & $\mathrm{p}$ & $\begin{array}{c}\text { Partial Eta- } \\
\text { squared }\end{array}$ & \\
\hline \multicolumn{3}{|c|}{6 Months } & & & & & & & & \\
\hline \multirow{4}{*}{2} & Angry & $2.82 \pm 1.6$ & & & & $A>H$ & 0.56 & 0.462 & 0.02 & 0.044 \\
\hline & Happy & $0.97 \pm 1.9$ & 3.38 & 0.040 & 0.11 & $A>N$ & 9.76 & $0.004 *$ & 0.26 & 0.006 \\
\hline & Neutral & $-2.68 \pm 1.5$ & & & & $\mathrm{H}>\mathrm{N}$ & 2.86 & 0.102 & 0.10 & 0.033 \\
\hline & Angry & $0.29 \pm 1.34$ & & & & $\mathrm{H}>\mathrm{A}$ & 4.26 & 0.048 & 0.13 & 0.022 \\
\hline \multirow[t]{2}{*}{14} & Happy & $4.02 \pm 1.67$ & 3.24 & 0.047 & 0.10 & $A>N$ & 0.11 & 0.746 & 0.004 & 0.050 \\
\hline & Neutral & $-0.33 \pm 1.24$ & & & & $\mathrm{H}>\mathrm{N}$ & 5.62 & 0.025 & 0.17 & 0.017 \\
\hline \multirow{4}{*}{16} & Angry & $-1.51 \pm 1.74$ & & & & $\mathrm{H}>\mathrm{A}$ & 8.26 & $0.008 *$ & 0.23 & 0.011 \\
\hline & Happy & $4.49 \pm 1.58$ & 4.38 & 0.017 & 0.14 & $N>A$ & 1.10 & 0.300 & 0.04 & 0.039 \\
\hline & Neutral & $0.73 \pm 1.25$ & & & & $\mathrm{H}>\mathrm{N}$ & 3.80 & 0.060 & 0.12 & 0.028 \\
\hline & 9 Mont & & & & & & & & & \\
\hline \multirow{4}{*}{21} & Angry & $-2.67 \pm 1.68$ & & & & $\mathrm{H}>\mathrm{A}$ & 9.59 & $0.004 *$ & 0.25 & 0.017 \\
\hline & Happy & $3.57 \pm 1.75$ & 3.45 & 0.038 & 0.11 & $N>A$ & 0.55 & 0.465 & 0.02 & 0.033 \\
\hline & Neutral & $-0.84 \pm 1.53$ & & & & $\mathrm{H}>\mathrm{N}$ & 2.52 & 0.123 & 0.08 & 0.050 \\
\hline & $12 \mathrm{Mon}$ & & & & & & & & & \\
\hline \multirow{3}{*}{9} & Angry & $-3.79 \pm 1.40$ & & & & $\mathrm{H}>\mathrm{A}$ & 10.53 & $0.003 *$ & 0.27 & 0.008 \\
\hline & Happy & $1.88 \pm 1.37$ & 4.17 & 0.021 & 0.13 & $N>A$ & 1.26 & 0.271 & 0.04 & 0.042 \\
\hline & Neutral & $-1.32 \pm 1.72$ & & & & $\mathrm{H}>\mathrm{N}$ & 2.74 & 0.109 & 0.09 & 0.033 \\
\hline \multirow{3}{*}{21} & Angry & $-2.62 \pm 1.79$ & & & & $\mathrm{H}>\mathrm{A}$ & 0.78 & 0.385 & 0.03 & 0.050 \\
\hline & Happy & $-0.43 \pm 1.65$ & 3.24 & 0.047 & 0.10 & $N>A$ & 6.53 & 0.016 & 0.19 & 0.017 \\
\hline & Neutral & $3.16 \pm 1.55$ & & & & $\mathrm{~N}>\mathrm{H}$ & 2.87 & 0.101 & 0.09 & 0.025 \\
\hline
\end{tabular}

$2{ }^{*}$ Comparison survived FDR correction. ${ }^{\mathrm{a}} \mathrm{A}=$ Angry, $\mathrm{H}=$ Happy, $\mathrm{N}=$ Neutral 


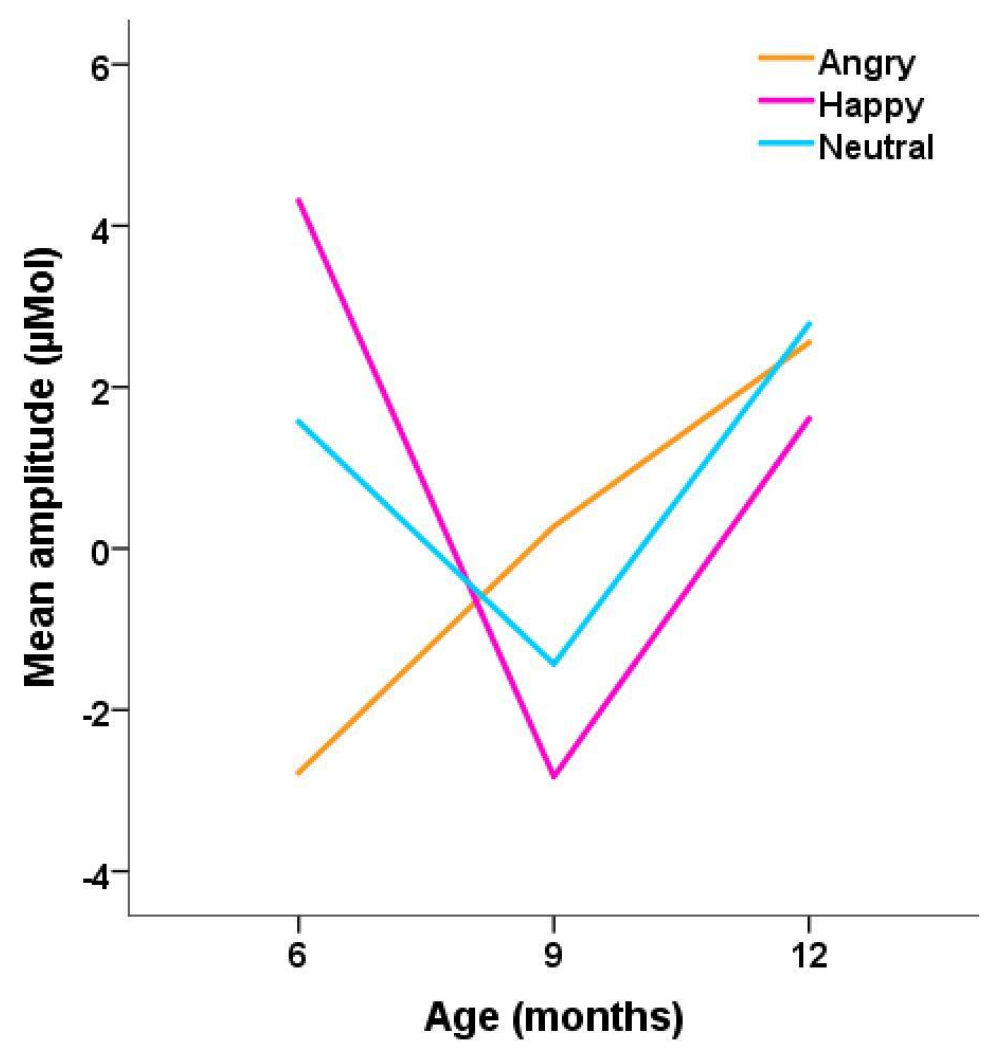

Figure 4 Mean amplitudes of Oxy-Haemoglobin concentration changes for angry, happy and neutral in channel 16 at ages of 6, 9 and 12 months.

4

5

6 


\section{Discussion}

The present study is unique in using a within-subject design to track the developmental trajectory of temporal cortical activation to human emotional (angry, happy) non-speech vocalisations across the first year of an infant's life. There are three main findings of note. First, at all age points (6, 9 and 12 months), we found a significant main effect of activation in temporal cortices in response to vocal emotional stimuli, particularly for happy (versus angry) vocalisations. Second, despite a lack of overall main age effect, right temporal (channel 16) responses to vocal emotional stimuli increased significantly with age, especially between 9 and 12 months. Third, infants' neural responses to vocal anger in the right hemisphere (channel 16) increased significantly with age, while sensitivity to vocal happiness did not, suggesting that infants may follow distinct developmental trajectories for processing angry and happy prosody.

Consistent with our prediction, temporal cortical activations to vocal emotions overall were consistently elicited in infants aged 6, 9 and 12 months. The temporal cortices play a key role in decoding acoustic features in human vocalisations (Belin \& Zatorre, 2000; Zhang, Zhou, \& Yuan, 2018), even before infants fully acquire language skills (Blasi et al., 2015; Grossmann et al., 2010; Missana et al., 2017). Emotional vocalisations carry both human voice and emotion features and have been found to be meaningful in infant neural responses at 3-7 months (Blasi et al., 2015; Grossmann et al., 2010; Grossmann et al., 2005). Findings from the present study not only expand the understanding of vocal emotion neural mechanisms beyond 7 months of infancy, but also confirm the ongoing development of temporal regions in decoding prosodic features in vocalisations between 9 and 12 months. There was no significant main effect for location in the longitudinal data and the age $x$ emotion $\mathrm{x}$ location interaction was driven by the age $\mathrm{x}$ emotion interaction effect in channel 
1 16. Although neural responses to emotional stimuli in channel 16 in the right hemisphere

2 resemble the right lateralised effect found in other infant and adult studies (Alba-Ferrara, Ellison, \& Mitchell, 2012; Grossmann et al., 2010; Ross \& Monnot, 2011; Zhang, Zhou, \& Yuan, 2018), we were unable to provide a laterality effect, which may require a larger sample.

Our findings suggest that there is a neural sensitivity preference in typically developing young infants for positive prosody over negative prosody, in line with findings from other neuroimaging studies of 7- and 8-month-olds (Grossmann et al., 2010; Grossmann, Striano, \& Friederici, 2005; Missana et al., 2017) and adults (Pinheiro, Barros, Vasconcelos, Obermeier, \& Kotz, 2017). Our report of enhanced brain responses to happy prosody support previous data that typically developing infants prefer happy voices early in life from birth (Mastropieri \& Turkewitz, 1999; Singh et al., 2002); alongside the emotional tones of infant-directed speech (Mehler et al., 1978). Social interactions with caregivers in healthy mother and young infant dyads are typically characterised by smiling faces and happy voices (Eisenberg, Cumberland, \& Spinrad, 1998; Malatesta, Grigoryev, Lamb, Albin, \& Culver, 1986), which promote mother-infant attachment and infant emotion regulation (Leigh, Nievar, \& Nathans, 2011; Lohaus et al., 2001; Thompson, 1997). Infants' sensitivity to, and interest in, happy vocalisations from birth and their familiarity with positive vocalisations from interactions with caregivers may drive infant cortical responses to prioritise responses to happy prosody. In 6-month-old infants, we also found enhanced left temporal responses (channel 2) to angry compared to neutral voices consistent with previous research (Grossmann et al., 2010), possibly suggesting enhanced neural processing of negative stimuli early in development. Sensitivity to negative vocal emotion serves as an adaptive function, which is not detected in the temporal region in brain studies until the 
latter half of an infant's first year (Vaish, Grossmann, \& Woodward, 2008). Surprisingly, we

2

have not found significantly greater neural responses to angry compared to neutral or happy at 9 or 12 months. This is the first study, as far as we are aware, with longitudinal data in the same infants from 9-to 12-months of age on neural responses to emotional vocalisations, so we are unable to compare this set of findings with others. However, we did find consistently increasing neural responses to angry vocalisations with age in the right temporal cortex (channel 16), which is discussed below.

Our second prediction that, overall, across all cortical regions, neural response to emotional prosody would grow incrementally with age was not supported. In the substatistical analysis, we found a channel 16 right hemisphere effect of age with increasing vocal sensitivity, especially between 9 and 12 months and especially in response to angry prosody. Our findings are in line with EEG evidence that the alpha power frequency to visual and auditory stimuli increases with age between 5 months and 4 years (Marshall, Bar-Haim, \& Fox, 2002; Michel et al., 2015). The incremental neural responses to emotional vocalisations from 6 months to 12 months extends previous research reporting that the strength of voice-selective neural responses become more prominent with the infant's age between 3 and 7 months (Blasi et al., 2011; Lloyd-Fox et al., 2012). Previous research also suggests that infants are going through a transitional period between 4 and 8 months before voice-sensitive neural responses become relatively stable after 9 months (Lloyd-Fox et al., 2017); therefore, the increasing neural sensitivity to emotional vocalisations after 9 months of age may suggest the incremental development of cortical specialisation. The question of when vocal emotion neural responses become specialised requires further investigation in infants beyond 1 year. 
did not follow a linear pathway. This non-linear neural development suggests that some channels may be sensitive to emotional vocalisations in general and not specialised to respond to specific emotions. Furthermore, this finding may reflect infants' rapid and variable pace of cognitive and social emotional development between 6-12 months, as with cognitive skills, such as language (Bates, Bretherton, \& Snyder, 1991; Fenson et al., 1994); and/or individual differences in exposure to vocal and communicative input by caregivers and others (e.g. siblings, daycare staff). Additionally, we speculate that the drop in neural responses to neutral and happy vocalisations in channel 16 at 9 months may reflect a widely known phenomenon, stranger anxiety, that peaks around 9 months and may lead infants to perceive all stranger vocal sounds as negative; or otherwise parse the incoming auditory stimuli differently than at other times (e.g. (Schore, 2001). However, this is the first study to examine vocal emotion processing longitudinally in the same infants between 6-12 months and we caution against further speculation in this emerging field.

Consistent with our third research question, the longitudinal analysis revealed distinct developmental trajectories for angry and happy vocalisations across the three time points. There were consistently enhanced neural responses to happy vocalisations over all time points $(6,9$, and 12 months), while infant neural responses to vocal anger were stronger with age. Infants prioritise interest to happy emotional vocalisations from birth (Mastropieri \& Turkewitz, 1999); they are better able to discriminate happy than negative expressions until around 6 months of age when they begin to shift attention to more negative vocalisation (Grossmann et al., 2010; Vaish et al., 2008). This social-emotional developmental trend is evident in social referencing by the end of the first year. From 9 months onwards, infants tend to show less behavioural exploration on hearing negative 
1 vocalisations in ambiguous situations (see Walker-Andrews, 1997; Mumme et al., 1996). Our

2 earlier study of the current sample reports that, at 6 months, infant neural responses to

3 angry, in contrast to neutral, vocalisations were positively associated with maternal directiveness i.e. the degree to which caregivers interact or comment in a caregiver-centred

5 way (Zhao, Chronaki, Schiessl, Wan, \& Abel, 2019). It is possible that infants perceive caregivers' re-directive or incongruent (to the infant) behaviour and this may evoke negative emotions in the infant, which may be reflected in enhanced neural responses to angry vocalisations. These findings support the non-linear development of the temporal region for processing vocal emotion in infancy (especially negative emotion such as anger) and confirm our prediction that the developmental time course of prosody processing may be different for different types of emotion (i.e. positive and negative). Our finding of changing neural response to vocal emotion across different infant ages are consistent with the notion that the brain undergoes a process of 'fine-tuning' to vocal emotional signals across the first year of life (Johnson, Grossmann, \& Kadosh, 2009; Kolb \& Gibb, 2011; Leppänen \& Nelson, 2009). This is the first longitudinal, within-subject fNIRS study of the neural correlates of vocal emotion development in human infants; however, there remain important limitations. We did not find a location effect. Replication of the present paradigm, with an even larger sample, may clarify localisation effects in infant neural processing of vocal emotion. Since our emotional stimuli consisted of one negative and one positive emotion, it is unclear whether the neural activations were emotion-specific (e.g. anger) or valence-specific (e.g. negative). It is also unclear whether the sensitivity for happy vocalisations reflects an innate preference or a learned one, as a result of familiarity with positive affect. This may be important in the context of family and parenting interventions. In addition, the stimuli used 
caregiver voices. Infants may be more responsive to their own mother's voice than other

2

voices (Dehaene-Lambertz et al., 2010; Walker-Andrews, Krogh-Jespersen, Mayhew, \& Coffield, 2011). Furthermore, subcortical regions and frontal regions may also be implicated in vocal emotion processing (Blasi et al., 2015; Blasi et al., 2011), but technical limitations of our particular fNIRS system and the present source-detector setting restricted our observation of these regions. Future studies of neural responses to emotional vocalisations should include frontal and subcortical regions, such as insula and hippocampus.

The present study provides novel evidence for the neural development of vocal emotion processing between 6 to 12 months of age. This is the first longitudinal study tracking infants' neural responses to emotional vocalisations beyond 8 months of age. Our findings support a pattern of progressive development of superior temporal cortical sensitivity to vocal emotion prosody in typically developing infants. These results have implications for understanding social-emotional development in typically developing infants. Our findings suggest that infant social emotional development is rapid; such developmental trajectories might begin from an even earlier age before 6 months and continue beyond the first year. Future research would benefit not only from examining broader age ranges of infants, but might also consider how inter-individual differences, cognitive development, early experience of caregivers and their mother's own emotion processing behaviour influence this social-emotional developmental trajectory. In the future, our potential to intervene effectively in at-risk infants, or in a trajectory of atypical development, will depend on our ability to understand what influences healthy development and the parameters of typical and atypical trajectories from infancy. 
1 Acknowledgements

2 The authors wish to thank the families who participated in the study.

3

4 Disclosure statement

5 Authors do not have conflict of interest to declare. 


\section{References:}

Alba-Ferrara, L., Ellison, A., \& Mitchell, R. L. C. (2012). Decoding emotional prosody: Resolving differences in functional neuroanatomy from fMRI and lesion studies using TMS. Brain Stimulation, 5(3), 347-353. doi:10.1016/j.brs.2011.06.004

Banse, R., \& Scherer, K. R. (1996). Acoustic profiles in vocal emotion expression. Journal of Personality and Social Psychology, 70(3), 614-636. doi:Doi 10.1037/00223514.70.3.614

Bates, E., Bretherton, I., \& Snyder, L. S. (1991). From first words to grammar: Individual differences and dissociable mechanisms (Vol. 20): Cambridge University Press.

Belin, P., \& Zatorre, R. J. (2000). 'What', 'where' and 'how' in auditory cortex. Nature Neuroscience, 3(10), 965-966. doi:Doi 10.1038/79890

Belin, P., Zatorre, R. J., Lafaille, P., Ahad, P., \& Pike, B. (2000). Voice-selective areas in human auditory cortex. Nature, 403(6767), 309-312. doi:Doi 10.1038/35002078

Benjamini, Y., \& Hochberg, Y. (1995). Controlling the False Discovery Rate - a Practical and Powerful Approach to Multiple Testing. Journal of the Royal Statistical Society Series B-Methodological, 57(1), 289-300.

Blasi, A., Lloyd-Fox, S., Sethna, V., Brammer, M. J., Mercure, E., Murray, L., . . Johnson, M. H. (2015). Atypical processing of voice sounds in infants at risk for autism spectrum disorder. Cortex, 71, 122-133. doi:10.1016/j.cortex.2015.06.015

Blasi, A., Mercure, E., Lloyd-Fox, S., Thomson, A., Brammer, M., Sauter, D., . . Murphy, D. G. M. (2011). Early Specialization for Voice and Emotion Processing in the Infant Brain. Current Biology, 21(14), 1220-1224. doi:DOI 10.1016/j.cub.2011.06.009

Boersma, P., \& van Heuven, V. (2001). Speak and unSpeak with PRAAT. Glot International, 5:341-347. 
Brigadoi, S., Ceccherini, L., Cutini, S., Scarpa, F., Scatturin, P., Selb, J., . . Cooper, R. J. (2014). Motion artifacts in functional near-infrared spectroscopy: A comparison of motion correction techniques applied to real cognitive data. Neuroimage, 85, 181-191. doi:10.1016/j.neuroimage.2013.04.082

Chronaki, G., Benikos, N., Fairchild, G., \& Sonuga-Barke, E. J. S. (2015). Atypical neural responses to vocal anger in attention-deficit/hyperactivity disorder. Journal of Child Psychology and Psychiatry, 56(4), 477-487. doi:10.1111/jcpp.12312

Chronaki, G., Broyd, S., Garner, M., Hadwin, J. A., Thompson, M. J. J., \& Sonuga-Barke, E. J. S. (2012). Isolating N400 as neural marker of vocal anger processing in 6-11-year old children. Developmental Cognitive Neuroscience, 2(2), 268-276. doi:10.1016/j.dcn.2011.11.007

Chronaki, G., Wigelsworth, M., Pell, M. D., \& Kotz, S. A. (2018). The development of crosscultural recognition of vocal emotion during childhood and adolescence. Sci Rep, 8(1), 8659. doi:10.1038/s41598-018-26889-1

Cohen, J. (1969). Statistical power analysis for the behavioral sciences. New York,: Academic Press.

Cohen, J. (1973). Eta-squared and partial eta-squared in fixed factor ANOVA designs. Educational and psychological measurement, 33(1), 107-112.

Cooper, R. J., Seib, J., Gagnon, L., Phillip, D., Schytz, H. W., Iversen, H. K., . . Boas, D. A. (2012). A systematic comparison of motion artifact correction techniques for functional near-infrared spectroscopy. Frontiers in Neuroscience, 6. doi:10.3389/fnins.2012.00147

Cooper, R. P., \& Aslin, R. N. (1990). Preference for infant-directed speech in the first month after birth. Child Development, 61(5), 1584-1595. 
Dehaene-Lambertz, G., Montavont, A., Jobert, A., Allirol, L., Dubois, J., Hertz-Pannier, L., \& Dehaene, S. (2010). Language or music, mother or Mozart? Structural and environmental influences on infants' language networks. Brain and Language, 114(2), 53-65. doi:10.1016/j.bandl.2009.09.003

Doan, S. N. (2010). The role of emotion in word learning. Early Child Development and Care, 180(8), 1065-1078.

Eisenberg, N., Cumberland, A., \& Spinrad, T. L. (1998). Parental socialization of emotion. Psychological Inquiry, 9(4), 241-273. doi:DOI 10.1207/s15327965pli0904_1

Ethofer, T., Anders, S., Wiethoff, S., Erb, M., Herbert, C., Saur, R., .. W Wildgruber, D. (2006). Effects of prosodic emotional intensity on activation of associative auditory cortex. Neuroreport, 17(3), 249-253. doi:10.1097/01.wnr.0000199466.32036.5d

Everdell, N. L., Gibson, A. P., Tullis, I. D. C., Vaithianathan, T., Hebden, J. C., \& Delpy, D. T. (2005). A frequency multiplexed near-infrared topography system for imaging functional activation in the brain. Review of Scientific Instruments, 76(9). doi:Artn $09370510.1063 / 1.2038567$

Faul, F., Erdfelder, E., Lang, A. G., \& Buchner, A. (2007). G*Power 3: a flexible statistical power analysis program for the social, behavioral, and biomedical sciences. Behav Res Methods, 39(2), 175-191.

Fenson, L., Dale, P. S., Reznick, J. S., Bates, E., Thal, D. J., \& Pethick, S. J. (1994). Variability in Early Communicative Development. Monographs of the Society for Research in Child Development, 59(5), R5-+.

Fernald, A. (1993). Approval and disapproval: Infant responsiveness to vocal affect in familiar and unfamiliar languages. Child Development, 64(3), 657-674.

Field, A., Miles, J., \& Field, Z. (2012). Discovering statistics using R: Sage publications. 
Fox, S. E., Wagner, J. B., Shrock, C. L., Tager-Flusberg, H., \& Nelson, C. A. (2013). Neural processing of facial identity and emotion in infants at high-risk for autism spectrum disorders. Front Hum Neurosci, 7. doi:10.3389/Fnhum.2013.00089

Fukui, Y., Ajichi, Y., \& Okada, E. (2003). Monte Carlo prediction of near-infrared light propagation in realistic adult and neonatal head models. Applied Optics, 42(16), 2881-2887. doi:10.1364/Ao.42.002881

Grandjean, D., Sander, D., Pourtois, G., Schwartz, S., Seghier, M. L., Scherer, K. R., \& Vuilleumier, P. (2005). The voices of wrath: brain responses to angry prosody in meaningless speech. Nature Neuroscience, 8(2), 145-146. doi:10.1038/nn1392

Grossmann, T., \& Johnson, M. H. (2007). The development of the social brain in human infancy. European Journal of Neuroscience, 25(4), 909-919. doi:10.1111/j.14609568.2007.05379.x

Grossmann, T., Oberecker, R., Koch, S. P., \& Friederici, A. D. (2010). The Developmental Origins of Voice Processing in the Human Brain. Neuron, 65(6), 852-858. doi:10.1016/j.neuron.2010.03.001

Grossmann, T., Striano, T., \& Friederici, A. D. (2005). Infants' electric brain responses to emotional prosody. Neuroreport, 16(16), 1825-1828. doi:10.1097/01.wnr.0000185964.34336.b1

Hargrove, P. M. (1997). Prosodic aspects of language impairment in children. Topics in Language Disorders, 17(4), 76-83.

Hayashi, A., Tamekawa, Y., \& Kiritani, S. (2001). Developmental change in auditory preferences for speech stimuli in Japanese infants. Journal of Speech, Language, and Hearing Research. 
Huppert, T. J., Diamond, S. G., Franceschini, M. A., \& Boas, D. A. (2009). HomER: a review of time-series analysis methods for near-infrared spectroscopy of the brain. Applied Optics, 48(10), D280-D298.

Johnson, M. H., Grossmann, T., \& Kadosh, K. C. (2009). Mapping functional brain development: Building a social brain through interactive specialization. Developmental Psychology, 45(1), 151.

Kennedy, J. J. (1970). The eta coefficient in complex ANOVA designs. Educational and psychological measurement, 30(4), 885-889.

Kisilevsky, B. S., Hains, S. M. J., Lee, K., Xie, X., Huang, H. F., Ye, H. H., . . W Wang, Z. P. (2003). Effects of experience on fetal voice recognition. Psychological Science, 14(3), 220224. doi:10.1111/1467-9280.02435

Kitamura, C., \& Burnham, D. (1998). Acoustic and affective qualities of IDS in English. Paper presented at the Fifth International Conference on Spoken Language Processing.

Kolb, B., \& Gibb, R. (2011). Brain plasticity and behaviour in the developing brain. J Can Acad Child Adolesc Psychiatry, 20(4), 265-276.

Leigh, P., Nievar, M. A., \& Nathans, L. (2011). Maternal Sensitivity and Language in Early Childhood: A Test of the Transactional Model. Perceptual and Motor Skills, 113(1), 281-299. doi:10.2466/10.17.21.28.PMS.113.4.281-299

Leppänen, J. M., \& Nelson, C. A. (2009). Tuning the developing brain to social signals of emotions. Nature Reviews Neuroscience, 10(1), 37-47. doi:10.1038/nrn2554

Li, Z., Park, B. K., Liu, W., Zhang, J., Reed, M. P., Rupp, J. D., . . Hu, J. (2015). A statistical skull geometry model for children 0-3 years old. Plos One, 10(5), e0127322. doi:10.1371/journal.pone.0127322 
1 Lloyd-Fox, S., Begus, K., Halliday, D., Pirazzoli, L., Blasi, A., Papademetriou, M., . . . Moore, S. (2017). Cortical specialisation to social stimuli from the first days to the second year of life: A rural Gambian cohort. Developmental Cognitive Neuroscience.

Lloyd-Fox, S., Blasi, A., Elwell, C. E., Charman, T., Murphy, D., \& Johnson, M. H. (2013). Reduced neural sensitivity to social stimuli in infants at risk for autism. Proceedings of the Royal Society B-Biological Sciences, 280(1758).

Lloyd-Fox, S., Blasi, A., Mercure, E., Elwell, C. E., \& Johnson, M. H. (2012). The emergence of cerebral specialization for the human voice over the first months of life. Social Neuroscience, 7(3), 317-330. doi:10.1080/17470919.2011.614696

Lohaus, A., Keller, H., Ball, J., Elben, C., \& Voelker, S. (2001). Maternal Sensitivity: Components and Relations to Warmth and Contingency. Parenting-Science and Practice, 1(4), 267-284. doi:10.1207/S15327922par0104_1

Malatesta, C. Z., Grigoryev, P., Lamb, C., Albin, M., \& Culver, C. (1986). Emotion Socialization and Expressive Development in Preterm and Full-Term Infants. Child Development, 57(2), 316-330. doi:Doi 10.2307/1130587

Marshall, P. J., Bar-Haim, Y., \& Fox, N. A. (2002). Development of the EEG from 5 months to 4 years of age. Clin Neurophysiol, 113(8), 1199-1208.

Mastropieri, D., \& Turkewitz, G. (1999). Prenatal experience and neonatal responsiveness to vocal expressions of emotion. Developmental Psychobiology, 35(3), 204-214. doi:10.1002/(Sici)1098-2302(199911)35:3<204::Aid-Dev5>3.0.Co;2-V

Maurage, P., Joassin, F., Philippot, P., \& Campanella, S. (2007). A validated battery of vocal emotional expressions. Neuropsychological Trends, 2(1), 63-74. 
McDonald, N. M., Perdue, K. L., Eilbott, J., Loyal, J., Shic, F., \& Pelphrey, K. A. (2019). Infant brain responses to social sounds: A longitudinal functional near-infrared spectroscopy study. Dev Cogn Neurosci, 36, 100638. doi:10.1016/j.dcn.2019.100638

Meek, J. (2002). Basic principles of optical imaging and application to the study of infant development. Developmental Science, 5(3), 371-380.

Mehler, J., Bertoncini, J., Barriere, M., \& Jassikgerschenfeld, D. (1978). Infant Recognition of Mothers Voice. Perception, 7(5), 491-497. doi:Doi 10.1068/P070491

Michel, C., Stets, M., Parise, E., Reid, V. M., Striano, T., \& Hoehl, S. (2015). Theta- and alphaband EEG activity in response to eye gaze cues in early infancy. Neuroimage, 118, 576-583. doi:10.1016/j.neuroimage.2015.06.042

Missana, M., Altvater-Mackensen, N., \& Grossmann, T. (2017). Neural correlates of infants' sensitivity to vocal expressions of peers. Dev Cogn Neurosci, 26, 39-44. doi:10.1016/j.dcn.2017.04.003

Morningstar, M., Nelson, E. E., \& Dirks, M. A. (2018). Maturation of vocal emotion recognition: Insights from the developmental and neuroimaging literature. Neurosci Biobehav Rev, 90, 221-230. doi:10.1016/j.neubiorev.2018.04.019

Mumme, D. L., Fernald, A., \& Herrera, C. (1996). Infants' responses to facial and vocal emotional signals in a social referencing paradigm. Child Development, 67(6), 32193237. doi:Doi 10.2307/1131775

Murphy, K. R., Myors, B., \& Wolach, A. (2014). Statistical power analysis: A simple and general model for traditional and modern hypothesis tests: Routledge.

Ockleford, E. M., Vince, M. A., Layton, C., \& Reader, M. R. (1988). Responses of Neonates to Parents and Others Voices. Early Human Development, 18(1), 27-36. doi:10.1016/0378-3782(88)90040-0 
1 Panneton, R., Kitamura, C., Mattock, K., \& Burnham, D. (2006). Slow speech enhances younger but not older infants' perception of vocal emotion. Research in Human Development, 3(1), 7-19.

Peirce, J. W. (2007). PsychoPy - Psychophysics software in Python. Journal of Neuroscience Methods, 162(1-2), 8-13. doi:10.1016/j.jneumeth.2006.11.017

Pena, M., Maki, A., Kovacic, D., Dehaene-Lambertz, G., Koizumi, H., Bouquet, F., \& Mehler, J. (2003). Sounds and silence: An optical topography study of language recognition at birth. Proceedings of the National Academy of Sciences of the United States of America, 100(20), 11702-11705. doi:10.1073/pnas.1934290100

Pinheiro, A. P., Barros, C., Vasconcelos, M., Obermeier, C., \& Kotz, S. A. (2017). Is laughter a better vocal change detector than a growl? Cortex, 92, 233-248. doi:10.1016/j.cortex.2017.03.018

Rogier, O., Roux, S., Belin, P., Bonnet-Brilhault, F., \& Bruneau, N. (2010). An electrophysiological correlate of voice processing in 4-to 5-year-old children. International Journal of Psychophysiology, 75(1), 44-47. doi:10.1016/j.ijpsycho.2009.10.013

Ross, E. D., \& Monnot, M. (2011). Affective prosody: What do comprehension errors tell us about hemispheric lateralization of emotions, sex and aging effects, and the role of cognitive appraisal. Neuropsychologia, 49(5), 866-877. doi:10.1016/j.neuropsychologia.2010.12.024

Scholkmann, F., Spichtig, S., Muehlemann, T., \& Wolf, M. (2010). How to detect and reduce movement artifacts in near-infrared imaging using moving standard deviation and spline interpolation. Physiological Measurement, 31(5), 649-662. doi:10.1088/0967$3334 / 31 / 5 / 004$ 
1 Schore, A. N. (2001). Effects of a secure attachment relationship on right brain development, affect regulation, and infant mental health. Infant Mental Health Journal: Official Publication of The World Association for Infant Mental Health, $22(1-2), 7-66$.

Singh, L., Morgan, J. L., \& Best, C. T. (2002). Infants' Listening Preferences: Baby Talk or Happy Talk? Infancy, 3(3), 365-394. doi:10.1207/S15327078in0303_5

Striano, T., \& Rochat, P. (2000). Emergence of Selective Social Referencing in Infancy. Infancy, 1(2), 253-264. doi:10.1207/S15327078in0102_7

Taga, G., \& Asakawa, K. (2007). Selectivity and localization of cortical response to auditory and visual stimulation in awake infants aged 2 to 4 months. Neuroimage, 36(4), 1246-1252. doi:10.1016/j.neuroimage.2007.04.037

Thompson, R. A. (1997). Sensitivity and security: New questions to ponder. Child Development, 68(4), 595-597. doi:Doi 10.2307/1132109

Trevarthen, C. (2017). The function of emotions in early infant communication and development New perspectives in early communicative development (pp. 48-81): Routledge.

Vaish, A., Grossmann, T., \& Woodward, A. (2008). Not all emotions are created equal: The negativity bias in social-emotional development. Psychological Bulletin, 134(3), 383403. doi:10.1037/0033-2909.134.3.383

Vaish, A., \& Striano, T. (2004). Is visual reference necessary? Contributions of facial versus vocal cues in 12-months-olds' social referencing behavior. Developmental Science, 7(3), 261-269. doi:10.1111/j.1467-7687.2004.00344.x 
1 Villringer, A., \& Chance, B. (1997). Non-invasive optical spectroscopy and imaging of human brain function. Trends in Neurosciences, 20(10), 435-442. doi:10.1016/S01662236(97)01132-6

Walker-Andrews, A. S. (1997). Infants' perception of expressive behaviors: differentiation of multimodal information. Psychological Bulletin, 121(3), 437-456.

Walker-Andrews, A. S., \& Grolnick, W. (1983). Discrimination of Vocal Expressions by Young Infants. Infant Behavior \& Development, 6(4), 491-498. doi:Doi 10.1016/S01636383(83)90331-4

Walker-Andrews, A. S., Krogh-Jespersen, S., Mayhew, E. M. Y., \& Coffield, C. N. (2011). Young Infants' Generalization of Emotional Expressions: Effects of Familiarity. Emotion, 11(4), 842-851. doi:10.1037/a0024435

World Health Organization (WHO). (2003). Child growth standards.

Zhang, D. D., Zhou, Y., Hou, X. L., Cui, Y., \& Zhou, C. L. (2017). Discrimination of emotional prosodies in human neonates: A pilot fNIRS study. Neuroscience Letters, 658, 62-66. doi:10.1016/j.neulet.2017.08.047

Zhang, D. D., Zhou, Y., \& Yuan, J. J. (2018). Speech Prosodies of Different Emotional Categories Activate Different Brain Regions in Adult Cortex: an fNIRS Study. Scientific Reports, 8. doi:10.1038/s41598-017-18683-2

Zhao, C., Chronaki, G., Schiessl, I., Wan, M. W., \& Abel, K. M. (2019). Is infant neural sensitivity to vocal emotion associated with mother-infant relational experience? Plos One, 14(2), e0212205. 